\title{
Insegurança pública: exceção como rotina, excepcionalidade como o normal no Rio de Janeiro, Brasil
}

\author{
Public Insecurity: exception as routine, exceptionality \\ as the norm in Rio de Janeiro, Brazil
}

Jacqueline de Oliveira Muniz (https://orcid.org/0000-0002-1481-414X) ${ }^{1}$

Fátima Regina Cecchetto (https://orcid.org/0000-0003-3080-5582) ${ }^{2}$

${ }^{1}$ Departamento de Segurança Pública, Universidade Federal Fluminense. R. Professor Hernani Melo s/n, São Domingos. 24210130 Niterói RJ Brasil. jacquelinedeoliveira. muniz@gmail.com ${ }^{2}$ Instituto Oswaldo Cruz, Fundação Oswaldo Cruz. Rio de Janeiro RJ Brasil.

\begin{abstract}
This article is an essay on the production of public insecurity, the yield that it brings as part of a regime of fear, and its effects of normalization of the practices of exception in the rule of law. The article focuses on the ethnographic work with the youth from the slums, together with state and local police from the State of Rio de Janeiro, as well as on a survey of documentary and journalistic sources on the internet, from 2017 to 2020. The reflections are guided by the discussion of the production of insecurity as a project of power. The logic of "protection" takes the place of security. The results point to the manufacture of diffuse and immediate threats as a resource for the imposition of a political economy of control and social regulation. The health crisis has aggravated the security crisis, keeping people on alert, with a feeling of urgency, living the immediate. Collective insecurity is not necessarily an unwanted outcome. It has been an expected and effective result, a strategic means through which to produce and sustain a project of exclusive and unequal power, for the few. Key words Public Security, Violence, State Control, Autonomous governments and police operations
\end{abstract}

Resumo Este artigo é uma construção ensaística sobre a produção da insegurança pública, seus rendimentos em termos de um regime do medo e seus efeitos de normalização das práticas de exceção ao estado de direito. Beneficia-se do trabalho etnográfico com a juventude de favela, policiais militares e guardas civis do Estado do Rio de Janeiro e, ainda, do levantamento de fontes documentais e jornalísticas na internet, no periodo de 2017 a 2020. As reflexões são orientadas pela discussão da produção da insegurança como um projeto de poder. A lógica da "proteção" assume o lugar da segurança. Os resultados apontam para a fabricação de ameaças difusas e imediatas como recurso para a imposição de uma economia política do controle e da regulação social. A crise sanitária aguçou a crise da segurança, mantendo as pessoas em regime de alerta, em urgência, vivendo o imediato. A insegurança coletiva não é um resultado necessariamente indesejado. Ela tem sido um resultado esperado e eficaz. Um meio estratégico para se produzir e sustentar um projeto de poder excludente e desigual, para poucos.

Palavras-chave Segurança Pública, Violência, Controle do Estado, Governos autônomos e operações policiais 


\section{Introdução}

Neste ensaio abordamos a produção da insegurança pública, seus rendimentos em termos de um regime do medo e seus efeitos de normalização das práticas de exceção ao estado de direito. As reflexões são orientadas pela discussão da produção da insegurança como um projeto autoritário de poder. Beneficia-se do trabalho etnográfico com a juventude de favela, policiais militares e guardas civis do Estado do Rio de Janeiro e, ainda, do levantamento de fontes documentais e jornalísticas, no período de 2017 a 2020. O texto está organizado em cinco seções: 1- Insegurança como projeto de poder; 2- Proteção de hoje, tirania de amanhã; 3- Faz-se uma guerra comercial para vender a paz; 4- Guerreiros, mercadores da proteção e profetas do caos; 5- Juízos finais.

\section{Insegurança como projeto de poder}

A insegurança tem servido como um espaço simbólico de condensação de todos os medos. Medo de morrer. Medo de sobrar. Medo de perder direitos. Medo de perder bens. Medo de adoecer. Medo do desemprego. Medo dos outros, com suas expressões desiguais de classe, de cor, de gênero, de orientação sexual, de adesão religiosa etc.

A insegurança é o lugar-síntese das desconfianças e temores vividos na gestão cotidiana de nossas vidas. Ela emerge como um constructo fundamental para o funcionamento de uma economia política do controle e da regulação sociais que condiz com a lógica neoliberal ${ }^{1}$, moldura que opera como um sistema complexo englobando dimensões econômicas, sociais, políticas e culturais, cujo alcance vai além da expansão do capital.

A produção da insegurança corresponde a um projeto de poder que tem produzido impactos sociais e políticos que minam a solidariedade e a cidadania. Através desse aparato vê-se o fortalecimento do regime do medo no imaginário, tanto do público quanto da polícia e outros agentes da justiça criminal, da ideia de um perigo iminente que requer a mobilização máxima para o combate ao inimigo. O discurso utilitário do medo ambiciona, alastrar, por toda a parte, o fato de que se trata de uma guerra a ser travada recorrendo a todos os meios disponíveis, inclusive o terror. Ao contrário de uma leitura de segurança pública como um "campo aberto, voltado para a busca de soluções de problemas relacionados à ordem pública"2, a análise da (in)segurança como um dispositivo de poder destaca o caráter processual dos modos de dominação de grupos interessados na disseminação de expedientes destinados a influenciar condutas, alterar as relações sociais e distorcer o papel do estado como promotor do bem público.

A deformação do Estado não é algo secundário na governamentalidade neoliberal ${ }^{3}$, mas profundamente enraizada nas reformas do bem -estar social e na privatização mercadológica da saúde, da educação, da segurança, envolvendo a responsabilização de indivíduos e famílias em vez do Estado ${ }^{4}$. Nesse cenário, a insegurança serve como um amálgama que empresta aparente unidade de sentido às experimentações singulares das violações vividas pelos sujeitos, no asfalto e na favela, em função de seus marcadores socioidentitários. Estes sujeitos, reelaborados nos discursos neoliberais de controle do crime ${ }^{5}$, são desejados como entes avulsos, alienados de suas redes de apoio e entregues ao cálculo utilitário das racionalidades do livre mercado. Espera-se que estas criaturas, repaginadas como libertas das proteções do Estado, se vejam e sejam vistas como expostas a todos os perigos nas suas interações. Diz-se: "infelizmente se vive em sociedade". O social passa a ser visto como uma ameaça em cada relação colocada sob suspeita; é a sociedade (sua solidariedade) que está sob ataque ${ }^{4}$.

Em cenários de generalização da desconfiança, próprios da construção de um regime do medo, os sujeitos estariam entregues a si mesmos. Porém com recursos pessoais escassos, limitados às bolhas virtuais e materiais ${ }^{6}$. Precisariam competir entre si por uma cidadania que se faz de mercado diante do acesso seletivo às garantias básicas e direitos fundamentais ${ }^{7}$. A produção e a disseminação de medos conduzem à aceitação coletiva da subordinação dos direitos sociais e civis às razões restritivas, discriminatórias e excludentes de (in)segurança. Tem-se a aceitação do direito como dispositivo estatal de dádiva e recompensa para os "bem-nascidos e bem-sucedidos" e como expressão de dívida, ameaça e sanção para os "malnascidos e inadaptados". Ou, limitados à construção de uma "política dos governados", onde a sociedade civil, seus direitos e paradigmas ficam restritos ao mundo classe média, deixando aos periféricos a gestão de uma "sociedade política" que alterna lógicas, direitos e construções como que à parte do mundo legal $\mathrm{e}$ constitucional $^{8}$.

Diante do agravamento da desconfiança e do temor coletivos, o tempo da cooperação encolhe, o tempo da suspeição aumenta, o tempo da resistência social às perdas sofridas parece congelar. Diante do medo aparelhado, abre-se 
mão de valores e conquistas democráticos em favor da proteção imediata de nossa vida sentida como em um estado continuado de ameaças. A reciprocidade na suspeição passa a corresponder, na gerência solitária de si e temerosa do outro, às trocas de acusação mútua de disseminação horizontalizada de riscos. Arrisca-se ao sentenciamento de ser ou estar envolvido com o crime ${ }^{9} \mathrm{e}$ toda sorte de "comportamentos antissociais" que contagiariam os espaços de convivência social.

É em um contexto de vigilância e punição elevados ao seu exagero, que se observa a emergência de um lugar moral de encontro de sujeitos amedrontados e solitários em seus temores. Este corresponde ao lugar de vítima apriorística que se situa aquém da experimentação de vitimização ${ }^{10}$. A vivência da violação direta seria apenas uma questão de tempo. A identificação com outras vítimas é só uma questão de espacialização metonímica. A indiferença em relação àqueles identificados como fontes de ameaça seria uma questão de subir cercas demarcando fronteiras. Assim, as vítimas probabilísticas e indiretas ingressariam em uma comunidade abstrata, expansiva e defensiva: "a sociedade ordeira e de bem". Aqui a empatia e a solidariedade voltam-se para o mesmo de si e contra um outro de nós.

A insegurança como projeto de poder beneficia-se dos expedientes de intolerância que funcionam como pedagogias do pensamento único em confronto com o pensamento comum. Conduz a produção de tutelas seletivas cuja engenharia social corresponde a incluir alguns para excluir vários. Estas exclusões revelam-se como terapias corretivas que vão da imposição de cura do deformado moral que merece uma chance, passando pela indiferença aos indesejáveis, até a eliminação dos irrecuperáveis, de quem não vale a pena investir, os "sementes do mal".

Insegurança, intolerância e exclusão situamse como dispositivos de poder que desafiam a administração pacífica de conflitos num mundo livre e plural. Quanto mais cegas são as fés mais amoladas vão se tornando as facas das agências de controle e regulação sociais, das polícias, em particular, que podem cortar língua do verbo da política, qualquer política, e rasgar a letra da lei. Regimes do medo se traduzem, na sua funcionalidade, em rotinas de policiamento que vão sendo substituídas por práticas excepcionais e heterodoxas de ação policial.

Como instituição de Estado, a polícia é disputada interna e externamente por grupos de interesse, ambiciosos de poder político, econômico e eleitoral. Assiste-se à recondução de seus objetivos fundantes, à medida em que tem sido capturada por agrupamentos que são expressão dos governos autônomos e não operam mais para garantir a gestão estatal e pública de populações e territórios. Não se trata de permitir que a polícia policie. Trata-se de promover uma polícia acuada pelo abuso político-eleitoral, e seu uso mercantil. Não se trata de administrar conflitos com o recurso potencial e concreto de força sob consentimento social e diante do império da lei ${ }^{11}$. Trata-se de (re)negociar o preço dos alvarás de concessão dos territórios para os domínios $\operatorname{armados}^{12}$. Encena-se o espetáculo operacional do "tiro, porrada e bomba" que repercuta ainda mais o temor. E que assim faça muito barulho à distância para alcançar os espaços nobres do asfalto e ameace, cada vez mais de perto, a periferia, com o volume de corpos de civis e de policiais vitimados e de coisas apreendidas para "fazer estatísticas". Trata-se de promover o medo de ser vítima de "bala perdida" ou de "bala achada". Trata-se de estimular o risco de "ficar preso na farda" policial que tem servido como um ícone da repulsa diante memória acumulada de violência e, também, um imã para atração compensatória de vendetas e outros acertos de contas. Controlada por grupos internos e externos que operam na lógica de empreender confinamentos do mundo popular por meio de cercas itinerantes e de estimular mobilidades espaciais e sociais negativas. Trata-se de dar vida, ali na vizinhança, às unidades autônomas de ódio, de ressentimento e de vingança compostas por autoproclamados "cidadãos de bem”. Suas cruzadas moralistas vivificam as "polícias de costumes", cujas práticas políticas de extorsão e as formas de gestão de mercados ilegais permitem sua revelação como "polícias de bens".

\section{Proteção de hoje, tirania de amanhã}

O medo disseminado não é um conselheiro confiável. Ele transforma as predições persecutórias sobre o amanhã em prescrições ameaçadoras no hoje. Induz ao cálculo antecipado e extenuante do imediato como recurso de gerência de si diante da proliferação das incertezas dramatizadas pelas narrativas do agravamento do temor. Estimula a feitura de uma contabilidade moral apriorística das fontes de risco. Um expediente defensivo de sobrevivência nas favelas frente às rupturas de rotina promovidas pela gestão governamental da "guerra contra o crime". O medo também produz moralidades que estabelecem clivagens de sentidos, práticas e desejos, forjando 
fronteiras e identidades, como a do macho alfa invulnerável à morte por bala ou por uma gripezinha.

O principal rendimento político da fabricação de medos corresponde a propiciar e legitimar um projeto autoritário de poder. Pois, quanto maior o sentimento generalizado de insegurança, maior a dificuldade de coesão social em torno de interesses comuns, de empatia pelo diferente e de mobilização coletiva pela sustentação de direitos e conquistas. Quanto mais agrava o temor, mais aumenta a oportunidade de adesão de indivíduos assustados a um pacto de submissão a quem promete "combater com firmeza e de uma vez por todas" o crime, a violência, a incivilidade, a desordem. Quanto mais aparelhado é o medo maior a possibilidade de subordinação a um pacto de sujeição que prometa proteção mais próxima do instantâneo dos sustos vividos, de forma direta acima da lei e aquém dos direitos.

O regime do medo e, por sua vez, a generalização das percepções de insegurança, é um governo de prontidão que mantém o subalterno de olhos abertos, em estado de atenção, para fazer o corpo reagir e contornar rapidamente às ameaças simbólicas e materiais que vêm de cima com os guerreiros do Estado, que saem de dentro com os domínios armados, que se espalham ao redor com os mercadores da proteção e que chegam do lado com as desconfianças recíprocas. Diz-se pragmaticamente na lida deste pandemônio diário: "é o que temos para hoje". Pular as cercas da suspeição generalizada, saltar as barreiras da exclusão, passar pelas barricadas dos direitos destituídos e atravessar as fronteiras sociais com os poucos capitais econômicos e simbólicos "contadinhos, sempre à conta". Tudo isso, fazendo uso de uma cidadania de programa de milhagens, com a qual se paga caro a cada parada social rumo ao asfalto e se acumula pontos morais pela adesão à sua ordem. Tudo isso para mostrar que se aceita a desigualdade social como natural e a mobilidade socioespacial declinante como destino. Tudo isso para se manter vivo, "cair pra dentro" do mercado e tentar não sobrar.

A navegação pela vida diária nas periferias é atravessada pelo acionamento de um sistema informal de alerta instituído para lidar com os sobressaltos constantes do "combate ao crime" ou das "disputas entre facções". Quem é ou vem de favela aprende a fazer uso, quando mede favela adentro ou quando põe o pé para fora, de uma "cartilha de boas práticas" para manobrar com os medos de "ser visto como envolvido", de "morrer nas mãos da polícia", de "servir de escudo do cri- me" e, ainda, de "fazer tudo certo e mesmo assim sobrar".

\section{Como funciona o circuito perverso da proteção}

O campo da segurança é o espaço do controle social pactuado e da regulação garantidora das liberdades. Suas ações preventivas, dissuasórias e repressivas são, por natureza, restritivas e invasivas. Por isso, estas devem ser consentidas pela sociedade e administradas pelo Estado. Por isso, a segurança precisa ser pública. Quando a segurança pública é pervertida em proteção particularizada, caminha-se do mundo livre do ir e vir para os espaços defensivos. Vai-se do mundo igualitário do 0800 gratuito, onde cabe todos, para a realidade desigual do 0300 dos cercados VIPs dos que pagam para entrar.

Proteger não é produzir segurança pública. A proteção é um recurso particularizado, desigual, excludente e paga-se por ela. É um bem de consumo operado e capitalizado por governos autônomos. Pode-se dizer que a lógica da proteção, incapaz de promover a segurança coletiva, introduz o medo como o conselheiro, a violencia como o cotidiano e o terror como o horizonte ${ }^{13}$. É isto que funda a aceitação de uma autoridade autoritária, acima das regras de convivência social, acima da lei. O protetor voluntarista de hoje, seja ele o musculoso simpático da academia, o traficante sangue bom da proximidade, o fortão boa pinta da esquina, o miliciano gente boa, será o seu tirano de amanhã. O libertador dos medos fabricados de agora será o achacador calculista que fabricará sucessivas ameaças para seguir com a venda de proteção. Este é o negócio da proteção que produz o controle ilegal sobre territórios e populações e, com isso, regula os mercados ilegais.

Para fazer funcionar o circuito perverso da proteção, há que promover crises de segurança, fabricando personagens reais ou fictícios que representem perigo, por suas condições sociais, pela cor de sua pele, pelo seu habitus associado ao criminoso, ao que precisa ser contido para que a "boa sociedade" continue indo ao shopping, à igreja, à escola. Estas ameaças continuadas levam a acordos precários e a alianças provisórias na gestão da vida social. Isto abre espaço para as lógicas defensivas de distanciamento social, do tipo "cada um no seu quadrado" que corroem a empatia, a solidariedade e a cooperação, expressas na máxima "farinha pouca, meu pirão primeiro".

Chegamos à exaustão da insegurança que termina no conto autoritário de uma autorida- 
de forte que promete trazer de volta a ordem e a normalidade que ela mesma ataca. Isto leva a tiranias, exercidas por governos ilegais e legais, legítimos e ilegítimos que promovem o uso do terror como estratégia de marketing de sua economia política criminosa. Amplia-se a imprevisibilidade com práticas de vigilantismo e justiçamento que possuem elevada visibilidade social e produzem a sensação de policiamento e justiça feitos no imediato.

As práticas de terror se tornam um grande espetáculo político com a promoção de uma guerra comercial contra o crime que justifica, em tempo contínuo, as práticas de exceção. Estas transformam as vidas e os direitos em mercadorias com valores e importância desiguais conforme as credenciais de cor, classe, gênero, orientação sexual, moradia e adesão religiosa. O tempo extraordinário da guerra subordina a gestão da vida ordinária. Legitimam-se as práticas excepcionais que colocam entre parêntesis o Estado de Direito que vai se tornando o direito do estado exercido pelo senhor da guerra da ocasião e pelos mercadores da proteção.

\section{"Faz-se uma guerra para vender a paz": uma propaganda política de alto impacto para o marketing do terror}

E o Rio de Janeiro continua lindo? O Rio continua sendo uma "verdadeira praça de guerra”, dizem os agentes da lei, a imprensa e muitos cariocas. Uma busca panorâmica no Google sobre a segurança pública evidencia uma galeria de imagens que retratam o modo como os homens da polícia, os caras da milícia e os meninos dos movimentos se veem, são vistos e querem ser notabilizados na eternidade das redes sociais. As imagens têm em comum a ostentação de performances provocativas, a exibição do poderio dos armamentos, as comemorações efusivas de vitória sobre o inimigo da vez, as apresentações dos saldos operacionais ou espólios dos vencidos, as demonstrações de lealdade combativa, as expressões gestuais violentas e as vestimentas que valorizam a disposição viril para o combate. Revela-se, por meio desta amostragem iconográfica, uma narrativa sobre a (in)segurança que se pretende hegemônica: a guerra como uma realidade inevitável entre as "forças da ordem" contra os "bandos armados" e de todos entre si.

A coleção de imagens veiculadas com um elevado impacto visual e alta visibilidade social, produzem uma grande encenação da tal guerra. Fazem aparecer uma polícia de espetáculo com seus homens de operações, uma "polícia dos bens" milicianos e uma rapaziada ostentação do tráfico em seus policiamentos e regulações ilegais dos mercados ilícitos. Ganham também destaque as fotos de pichações, de barricadas, de sentinelas e de mapas que delimitam os territórios sob domínio armado dos governos autônomos ilegais. Vê-se, ainda, nas buscas no Google, os registros visuais das frequentes disputas territoriais entre estes governos. Quem te viu que te compre, diz a máxima que nos faz acreditar: Habemus bellum! A guerra é real em suas práticas discursivas de verdade.

A guerra contra o crime, produzida ora com a adesão populista de governantes, ora como demonstração de força político-econômica contra eles, já dura mais de três décadas sem alcançar vitória ou derrota. A guerra é a continuação da economia política criminosa itinerante e em rede por meios publicitários. Como um empreendimento empresarial tem que seguir sendo vista como uma jornada sem fim, uma luta indispensável para os negócios da proteção e necessária para animar a moral dos bons costumes. Ela é a dimensão publicitária de impacto do marketing do terror, a serviço do regime do medo e de seu projeto autoritário e lucrativo de poder. Para generalizar o sentimento individual de insegurança e promover o agravamento coletivo do temor, é fundamental fazer muito barulho, ter bastante tiroteio, incitar confrontos armados e distribuir balas perdidas. Torna-se útil usar softwares que orientem percursos seguros, e evitem cair nas "áreas de risco" ou em barreiras policiais, do tráfico ou da milícia. Para sair de casa, antes ou depois dos confrontos armados, tornou-se lugar comum consultar os Apps "Fogo Cruzado", "Onde tem tiroteio" e o Blog "Pista News". Afinal, é imprescindível interromper rotinas, paralisar o trânsito, restringir a circulação, possibilitar coberturas midiáticas em tempo real e disseminar rumores. Tudo isso para produzir o efeito barata tonta na população de perto na periferia, onde tudo acontece, e de longe nas zonas nobres, onde se assiste do sofá a guerra nos aplicativos. Para manter todos à beira de um ataque de nervos e perdidos feito cego em tiroteio é preciso muitos sons, luzes, fúrias e ação: palavras de ordem, sirenes intermitentes, rajadas rítmicas, giroflex ligado, faróis altos e miras a laser em prontidão para pronto-emprego coreográfico na odisseia operacional do comando em ação.

A guerra é a exaltação do dispêndio intimidatório com elevada visualidade que necessita de uma polícia de espetáculo, uma polícia ostentação, uma polícia de operações. Uma força baru- 
lhenta que se faz notar e que se exibe "esquentando a chapa". A guerra contra o crime é, antes, uma ficção real. Seu realismo torna-se mais verdadeiro quanto mais se afasta da realidade da segurança pública e imita a extravagância e o exagero dos filmes de ação.

\section{Um teatro de operações policiais, políticas e comerciais: autopromoção em alta visibilidade}

Todo dia eles fazem tudo sempre igual, acordam para vida das operações, despertam os territórios populares com alguma intervenção. Do nada, por terra e pelo ar, aparecem os caveirões botando polícia pelo ladrão. Não se vê o vai-evem convencional e monótono dos patrulhamentos ostensivos individualizados que produzem controle do território e da população. Não se trata de policiar ou de produzir efeitos acumulados dissuasórios e preventivos através da repressão qualificada e com foco. Trata-se de produzir resultados repressivos de grande repercussão, porém de impacto criminal pontual, limitado no tempo e restrito no espaço às custas de vultuosos recursos públicos. Assiste-se à excepcionalidade feita rotina da tomada de assalto de um perímetro reduzido por numerosos efetivos policiais. Tem-se uma correria errante e intermitente de frações de tropa nas periferias à dentro, convertidas em "territórios instáveis". Trata-se de efetuar incursões e cercos nas "propriedades da polícia"14 nos territórios da guerra, com ou sem finalidade política explícita. Missão política dada é missão publicitária cumprida: os procedimentos operacionais padrão de patrulhamento cedem lugar às chamativas "táticas de guerrilha". Troca-se a polícia cotidiana da preservação da ordem pela presença provisória do enxuga gelo da polícia de operações. Reproduz-se o sobe-desce morro dando vida à síndrome do cabrito que imobiliza expressivos contingentes policiais, produzindo escassez de policiamento nas ruas da cidade. $\mathrm{O}$ sobre emprego policial nos teatros de operações, a um só tempo, exaure a capacidade operacional existente, diminui a cobertura ostensiva e compromete a pronta-resposta nas chamadas emergenciais. Com a banalização dos espetáculos operacionais abdica-se da polícia do antes que algo aconteça, retarda a polícia do durante a ocorrência e a adia polícia do depois do fato consumado.

As chamadas operações especiais cumprem um papel fundamental no conjunto das atividades de policiamento. Sua razão de ser é a atuação em eventos críticos que apresentam alto risco de mortes de policiais, vítimas e agressores. Esta é a origem da criação de corpos táticos especializados e bem treinados, cuja missão é a reversão tática de situações críticas com "baixas zero". O estado de sua arte é fazer o relógio andar para trás, reduzindo os riscos e os perigos reais em cenários complexos. Este o motivo pelo qual as operações especiais são um recurso nobre e caro cujo emprego deveria ser esporádico e extraordinário para garantir sua disciplina tática e sua superioridade de método.

No Rio, as operações especiais viraram "operações policiais" distanciando-se de sua doutrina específica, de seu caráter "especializado" original. Converteram-se no modo prioritário e recorrente de ação policial, instituindo uma outra serventia que não corresponde ao controle do crime comum e das redes criminosas como se imagina. A despeito do que os policiais acreditam que devam ser o emprego técnico-profissional das operações policiais, elas cumprem propósitos estranhos à sua função inicial: fazer a guerra! Retumbar na ordem do dia, a teatralização da repressão como um fim em si mesma, indispensável à implantação do regime do medo. Busca-se manipular com a dimensão mais visível do trabalho policial aos olhos dos mortais: a repressão que consiste na ação policial concreta e em tempo real. Afinal, a natureza do fazer policial é repressiva quando dissuade e previne crimes, violências e desordens. $\mathrm{O}$ seu rendimento político-econômico torna-se mais significativo com a fácil mobilização dos recursos coercitivos em escala por meio das operações policiais. Quanto mais "trocação" de tiros, cisma, provocação e tretas amplificadas melhor para autopromoção com alta visibilidade dos negócios da proteção.

Se a guerra é uma desmesura, as operações policiais rotinizadas são um desperdício de recursos materiais e humanos de grande valor para o regime do medo. Ela é a exuberância de um espetáculo dramático que tende ao trágico no horror das mortes: ampliar a insegurança e acirrar o temor. A fabricação da guerra se faz acompanhar de um processo em curso de emancipação predatória e particularização do poder de polícia que propicia a emergência e a chancela dos governos autônomos criminosos que administram territórios e regulam mercados ilícitos.

Sabe-se que a guerra não combate os grupos armados. A guerra cria os grupos armados que a legitimam e a perpetuam. Governa-se com o crime e não contra ele. Regimes do medo dão vida a uma economia política do crime que regula e incentiva mercados ilegais de serviços e bens essenciais. Na periferia paga-se várias vezes pelas 
mesmas mercadorias políticas ${ }^{15}$. Os bens imobiliários, o gato de luz, a água puxada, o botijão de gás, o transporte alternativo e o Gatonet podem ser cobrados repetidamente por conta da instabilidade e mudanças dos domínios armados e, ainda, pela arrecadação de impostos informais por grupos rivais.

Os governos autônomos ilegais precisam de uma medida de convivência, conveniência e conivência dos poderes públicos para funcionarem e prosperarem como, por exemplo, as milícias. Se faz a guerra para vender a paz do arrego, a paz da propina, para subir o preço do alvará da firma e do aluguel nas áreas populares. O Estado parece operar como uma grande agência reguladora que terceiriza as funções de governo e arrenda seus territórios para os domínios armados.

Delineia-se um tipo criminoso de empreendedorismo com revestimento neoliberal, sintetizado na frase de um policial militar entrevistado “cada um faz seu capitalismo". Nos mercados ilícitos há um lugar profícuo de oportunidades individuais para quem tem o poder de fazer descumprir a lei. O poder de polícia pervertido em poder do policial. Há que negociar um lugarzinho para fazer um pé de meia junto aos negócios da proteção. Tem um ditado policial que diz que "No Rio, [o policial] ou se omite, ou se corrompe ou vai para guerra”. Parece mais adequado dizer que a ida para guerra abre uma avenida para a corrupção e justifica a omissão na execução dos policiamentos públicos.

Guerrear é preciso. Cada um com sua guerra particular para manter ou expandir os seus negócios. No Rio de Janeiro, os arranjos políticos com os domínios armados no atacado são incapazes de absorver e coordenar os acertos policiais no varejo. Cada unidade operacional, cada guarnição e, no limite, cada policial pode fazer, de forma independente, a sua própria “operação policial" e promover a sua guerra particular, em nome de algum interesse público, ambições corporativistas e em seu próprio nome. Não se explicita uma unidade de comando na gestão dos policiamentos públicos e nem se observa uma unidade de comando nas atividades policiais ilegais. A inversão informal e a fragmentação invisível da cadeia de comando e controle policial pela autonomização e particularização do poder de polícia, estimula um tipo de liberalidade policial para a exploração de mercados ilícitos.

A articulação com os mercados ilícitos pelo topo se dá por uma lógica de conflito latente e manifesto com os variados acordos saídos da base da pirâmide policial: o papo reto é com as praças.
Têm-se disputas internas por fatias do mercado ilícito nos territórios populares entre integrantes policiais do alto e do baixo escalão e dentro dos mesmos níveis hierárquicos. Os contratos com os grupos criminosos, se tornam ainda mais instáveis e de baixa confiabilidade, exigindo atuações violentas ostentatórias, de parte a parte, para fazer valer e atualizar as regras precárias de um jogo econômico milionário. A violência e a corrupção policiais são dois lados da mesma moeda negociada dos mercados ilegais que dão lastro ao ajuste dos arregos. Atrás de policiais que matam e que morrem na guerra comercial contra o crime, há uma polícia enfraquecida institucionalmente e um governante vulnerável, algemado em seu gabinete. A existência de "batalhas simultâneas e autônomas" mostram o quanto o governante que discursa pela guerra contra o crime se torna ele mesmo prisioneiro ou refém de seu discurso: não governa os meios de força apenas serve de porta voz e porta-bandeira.

\section{Do varejo do arrego individual ao atacado miliciano}

No meio da guerra veio a peste atrapalhando as operações de todo dia. Têm-se notícias etnográficas da queda dos capitais dos domínios armados durante a pandemia da COVID-19. "Caiu a arrecadação", dizem as denúncias sobre a mineragem fominha e as reclamações sobre a redução do fluxo nas bocas de fumo. Ouve-se falar do delivery formiguinha do tráfico para atender clientes em isolamento social e da intensificação dos "perímetros" na cobrança de proteção nas áreas de milícia. $\mathrm{O}$ pandemônio das extorsões varejista de policiais avulsos e no atacado miliciano seguiu destemido desafiando a pandemia. $\mathrm{Na}$ favela, a guerra pelo domínio territorial armado é um problema de governo. Nem uma, nem outra é questão de Estado. Morrer de COVID-19 e/ou morrer pelo crime, eis a questão. Quem mora em locais sob domínio miliciano é coagido a pagar o mesmo imposto várias vezes: paga para o Estado, paga para o governo miliciano. "Só falta pagar pra respirar" dizem os moradores e comerciantes.

O CNPJ do crime não pode morrer. Sem arrecadação, cai a contribuição miliciana para o "caixa dois" de campanha eleitoral, perde-se poder no território e influência política. As carreiras políticas se tornam um investimento fundamental, uma lavanderia eficaz do dinheiro criminoso. A crise sanitária é uma janela de oportunidade para fortalecer negócios ilícitos das milícias. Há que seguir no vácuo deixado pelas operações po- 
liciais para ampliar soberanias, garantir monopólios, atualizar os contratos de extorsão.

Milicianos não estão escondidos e nem são invisíveis. Saem do Estado, têm endereço e trabalho fixo, circulam entre autoridades, participam de festas VIPs, fazem a segurança de gente importante. Estas são suas credenciais. E o diferencial da polícia dos bens é poder manipular de dentro a polícia do bem. O plano de negócios miliciano traz a vantagem de vender a ordem que ele mesmo ameaça com o marketing da guerra. Na terra prometida para a milícia "poupam-se vidas", suspendendo a rotina das operações policiais e trazendo a rotina ostensiva da extorsão. Tem-se a concessão estatal da função de governo com o controle territorial, a regulação do mercado e a valorização dos alvarás das firmas para custear a trégua, com o suporte de dinheiro e armas. A mineiragem contumaz, cobra alto pela oferta de estabilidade para o capital das transações criminosas girar. Afinal, na guerra da polícia de operações a acumulação da violência compromete a acumulação do capital criminoso. Os arregos pagos no varejo policial pulverizado fragilizam a capacidade de investir e multiplicar os dividendos do crime. Já o arrego do atacado miliciano evita, pelo tempo acordado, as perdas e prejuízos dos confrontos armados. $\mathrm{O}$ arrego concede a paz finita. Ele carrega, portanto, a benevolência intimidadora: não vai morrer criança, não vai morrer polícia, não vai morrer morador. Sorria ninguém precisa morrer se pagar o alvará. Para um bom miliciano, uma operação policial basta para vender previsibilidade em acordos precários.

\section{Guerreiros, mercadores da proteção e profetas do caos: insegurança, intolerância e exclusão}

Para se construir um regime do medo e naturalizar suas práticas de exceção como o "remédio amargo" contra a cidadania, mas a seu favor, não basta a disposição dos senhores da guerra e a adesão dos seus mercadores da proteção. Não basta o peito de pombo e a cara feia da autoridade de ocasião, a oferta das mercadorias ilegais mais baratas que no asfalto, a promoção dos "difíceis ganhos fáceis"16. A Espada pode muito, mas não consegue manter seu poder sozinha. Precisa de alianças políticas e acordos criminais. O mercado ilegal pode bastante com a força da espada, mas não consegue tudo. Necessita fidelizar fornecedores e clientes. $\mathrm{O}$ medo é um dispositivo afetivo potente, mas requer uma liga firme para grudar nas pessoas. $\mathrm{O}$ guerreiro e o mercador precisam do profeta e da sua pregação moralista para nos convencer das vantagens da sujeição. É indispensável um discurso cativante do medo que leve os sujeitos a desejarem o seu cativeiro. A eficácia simbólica vem com a crença que serve como cimento, uma tecnologia de legitimação da autoridade autoritária. Há um tripé violento que articula e funde o guerreiro da sujeição, o mercador dos negócios da proteção e o profeta do medo numa espécie de santíssima trindade opressiva que articula insegurança, intolerância e exclusão.

A exploração da insegurança introduz uma narrativa de perigos constantes e ameaças difusas que estruturam as vivências dos sujeitos pelos medos de morrer e de sobrar. A retórica do medo extremado é péssima conselheira conduzindo a desconfiança prévia como modo de interagir. Os inimigos vão do estranho ao conhecido, incluindo a suspeição das pessoas da nossa convivência como os vizinhos, parentes, amigos etc. As máximas defensivas, confie desconfiando e mantenha sempre um pé atrás, são fortalecidas.

A generalização da insegurança leva a intolerância como um recurso defensivo e violento acionado diante de sucessivas ameaças. A intolerância permite a desvalorização do pensamento comum, produto de embates, consensos e acordos entre sujeitos plurais em favor do pensamento único, impositivo, assentado na fantasia de uma sociedade homogênea e sem dissenso. A pedagogia do pensamento único instrumentaliza e legitima tutelas seletivas entre os indivíduos que legitimam a exclusão como política para quem está no andar de baixo da hierarquia social manobrando com sua situação desigual. Excluir para incluir indivíduos em situação de vulnerabilidade social corresponde a imposição de terapias corretivas. Somente para quem não se encaixa em uma concepção de ordem exterior, de cima para baixo, mantenedora do status quo branco, masculino, antigênero, heteronormativo etc. Serve para reforçar as barreiras sociais fortalecendo a criação de confinamentos sociais, "cada um no seu quadrado", que retroalimenta a insegurança. O tripé insegurança-intolerância-exclusão dá a liga e faz acreditar que "cada cabeça é uma sentença" para experimentar o escracho libertário contra o outro. Mas oculta que uma sentença justa só para si mesmo, cega em sua fé, faz a faca ficar mais amolada e cortar para todos os lados, incluindo o próprio lado.

A esta altura parece óbvio que um projeto autoritário construído sobre o aparelhamento do medo e da insegurança, faça uso de uma política do sobressalto. Produz-se sustos na população promovendo tragédias anunciadas diárias. Tem- 
se, então, o teatro mandonista dos surtos de autoridade que encenam que fazem e acontecem para obterem mais poder nos negócios da proteção. Por fim, dramatizam-se os soluços operacionais com a espetacularização de sucessivas operações policiais, pontuais e de efeito anti-criminal limitado, mas de elevada visibilidade social. Assim, se renova a crença no profeta do caos de que se vive numa situação fora do controle, que segue exigindo ações de exceção dos guerreiros na luta contra o mal para deixar o mercador da proteção trabalhar no crime.

\section{Juízos finais}

Como buscou-se evidenciar, o medo e a insegurança generalizados são péssimos conselheiros porque fazem prosperar demandas autoritárias de ordem. A segurança pública em sociedades democráticas, livres, igualitárias e plurais corresponde a garantia, em larga escala, da circulação regular, previsível e equitativa de ideias, pessoas, bens e serviços dentro e entre as cidades. A segurança pública ultrapassa a exclusividade, a intensidade e a qualidade das ações policiais cujos efeitos são sempre limitados e provisórios no tempo e no espaço, por melhor que as polícias possam fazer. A segurança pública tem como base estrutural das ações policiais de controle e regulação, as dinâmicas de mobilidade social e espacial e o acesso universal aos direitos e bens fundamentais. É isto que amplia o efeito preventivo e dissuasório do trabalho policial. A segurança pública ultrapassa o imediato do medo porque pavimenta um caminho que vai do aqui-e agora do nosso presente para o daqui-a-pouco no amanhã do nosso futuro. Já o regime do medo como um projeto de poder, promove o enxuga gelo da repressão como fim em si mesmo com a fabricação e o aparelhamento de crises de segurança. Para que um projeto autoritário prospere, o horizonte e os caminhos sociais têm que ser encurtados, presos a um presente instável de um futuro imprevisível. Quanto mais presentista, condensado, apressado e imediato for o tempo social, por conta do agravamento do temor, mais atraentes se tornam as propostas autoritárias que se apresentam como diretas, simples e sem mediações. Quanto mais os espaços sociais forem excludentes com mobilidades reversas que reforçam as barreiras dos isolamentos e as cercas dos distanciamentos sociais, mais atraentes se tornam as promessas por uma ordem autoritária que se acredita que funcione por ser unitária, uniforme e impositiva.

A segurança pública tem que voltar a ser administrada pelo Estado e não ser mais terceirizada para firmas clandestinas, grupos armados, etc. Só assim a insegurança deixará de ser um projeto político-criminoso milionário que tem dado certo entre nós.

\section{Colaboradores}

JO Muniz e FR Cecchetto participaram igualmente de todas as etapas de elaboração do artigo. 


\section{Referências}

1. Dardot P, Laval C. A Nova Razão do Mundo: ensaios sobre a sociedade liberal. São Paulo, Boitempo; 2016.

2. Costa TA, Lima SR. Segurança Pública. In: Lima RS, Ratton JL, Azevedo RG, organizadores. Crime, Polícia e Justiça no Brasil. São Paulo: Contexto; 2014.

3. Foucault M. Segurança, território e população. São Paulo: Martins Fontes; 2008.

4. Brown W. In The Ruins of Neoliralism: The Rise of Antidemocratic Politics in The West. Nova York: Columbia University Press; 2019.

5. Garland D. The Culture of Control: Crime and Social Order in Contemporary Society. Chicago: The University of Chicago Press; 2001.

6. Bauman Z. Vigilância Líquida. Rio de Janeiro: Zahar; 2014.

7. Muniz J, Patrício L. A segurança Pública da Constituição: direitos sob tutela de espadas em desgoverno. In: Santos Jr B, Valim R, organizadores. 1988/2018. 30 Anos da Constituição Federal do Brasil. Imprensa Oficial; 2019.

8. Chatterjee P. The Politics of the Governed. Reflections on Politics in Most of the World. Nova York: Columbia University Press; 2004.

9. Cecchetto F, Muniz J, Monteiro R. A construção social do envolvido com o crime. Cad CRH 2018; 31(82):99116.

10. Cecchetto F, Muniz J, Monteiro R. A produção da vítima empreendedora de seu resgate social: juventudes, controles e envolvimentos. Cien Saude Colet 2018 23(9):2803-2812.
11. Muniz J, Proença D. Muita politicagem, pouca política os problemas da polícia são. Estud Av 2007; 21(61):159-172.

12. Muniz J, Miranda A. Tá tudo dominado: Domínios Armados e governo de mercados ilegais. Rio como método. Ed Universidade da Califórnia; 2019. [no prelo].

13. Muniz J, Proença Jr D. A ameaça da proteção. Jornal Valor Econômico; 2006.

14. Reiner R. The politics of police. Toronto: University of Toronto Press; 1991.

15. Misse M. Mercados ilegais, redes de proteção e organização local do crime no Rio de Janeiro. Estud Av 2007; 21(61):139-157.

16. Batista VM. Difíceis ganhos fáceis. Drogas e Juventude pobre no Rio de Janeiro. Pensamento Criminológico 2. Rio de Janeiro: Ed Revan; 2003.

Artigo apresentado em 20/11/2020

Aprovado em 28/05/2021

Versão final apresentada em 30/05/2021

Editores-chefes: Romeu Gomes, Antônio Augusto Moura da Silva 